\title{
Knowledge and practices of iodized salt consumption among pregnant women in Galle district
}

\author{
De Zoysa GED ${ }^{1}$, Hettiarachchi $\mathbf{M}^{2}$, Jayathilaka KAPW ${ }^{1}$, Liyanage $\mathrm{KDCE}^{3}$ \\ Department of Biochemistry ${ }^{1}$, Nuclear Medicine Unit ${ }^{2}$, Department of Community Medicine ${ }^{3}$, Faculty of \\ Medicine, University of Ruhuna, Galle, Sri Lanka. \\ Correspondence: $\quad$ Dr. G.E.D. De Zoysa \\ Department of Biochemistry, Faculty of Medicine, University of Ruhuna, Galle, Sri Lanka. \\ e-mail:ericdezoysa@yahoo.com
}

\begin{abstract}
Introduction: Sri Lanka introduced national salt iodization programme in 1995 to control iodine deficiency disorders (IDD) as iodized salt is the main source of iodine in the population. Although Sri Lanka achieved a satisfactory control of IDD in 2005, a recent study showed that iodine nutrition in pregnant women in Sri Lanka is far below the WHO recommendation. Lack of knowledge on iodized salt and improper practices of its usage may cause iodine deficiency during pregnancy.

Methods: Study was conducted in Bope-Poddala health division of Galle District in the Southern province. Pregnant women $(n=425)$ with gestational age $\leq 12$ weeks were studied. An interviewer administered questionnaire was used to collect data.

Results: Forty percent of pregnant women in the sample had poor knowledge on iodized salt and the importance of iodine in the diet. Less than $50 \%$ of subjects were aware of bad consequences of maternal iodine deficiency on their babies and about $50 \%$ of them had improper practices on iodized salt usage. A poor correlation between the good knowledge and proper practices, were observed.

Conclusion: Overall knowledge about iodine and iodized salt is not satisfactory and the health educational programmes expressing the importance of eliminating IDD at various levels is important to prevent iodine deficiency during pregnancy.
\end{abstract}

\section{Introduction}

Sri Lanka introduced the national salt iodization programme in 1995 as a main strategy to control iodine deficiency disorders (IDD). Further, by legislation it was made compulsory to iodize the salt made for human consumption and the level of iodine in salt at the consumer level was recommended as 15 - 30 ppm. In 2005, it was declared that Sri Lanka achieved a satisfactory control of IDD (1).

Iodized salt is the main source of iodine in Sri Lankan population. It was reported that the iodized salt coverage with adequate iodine $(>15 \mathrm{ppm})$ at household level was $90.1 \%$ (by titration method) according to the survey on Iodine Nutrition Status in Sri Lanka in 2005 (2). Contrary to this, another study in 2010 reported that only $69.4 \%$ of salt at household level contained an adequate iodine concentration in Sri Lanka (3). Even though Sri Lanka was categorized as a country with adequate iodine intake and having iodine nutrition as optimal (4), those estimations were based on the iodine status of the school aged children. This may not reveal the true situation of iodine nutrition in the most vulnerable groups such as pregnant women. A recent study showed that iodine nutrition in pregnant women in Sri Lanka was far below the WHO recommendation of $150 \mu \mathrm{g} / \mathrm{L}$ of urinary iodine (5). 
With this background it is important to find out possible causes for the poor iodine nutrition in our population especially among pregnant women. A recent study showed that, only $64 \%$ of the salt products available in the market contained iodine within the recommended range of $15-30 \mathrm{ppm}$ (6). In addition to the unsatisfactory iodine content, lack of knowledge about the iodized salt and improper practices regarding its usage may contribute and therefore worth to be investigated. As such, this study was conducted in the Bope-Poddala health division of the Galle District with an aim to assess the knowledge and practices on consumption of iodized salt among pregnant women.

\section{Methods}

This study was conducted in Bope-Poddala health division of the Galle District in the Southern province during the period of July 2012 to September 2013. Maternal and child health services in the health division are provided through five antenatal clinics belonging to17 public health midwife (PHM) areas.

All the pregnant women visiting antenatal field clinics during the above period were considered as the study population and all with gestational age: $\leq 12$ weeks (as judged by the date of last menstrual period) were included in the study. The number of pregnant women to be included in this study was calculated based on WHO, 1991 (7).

Minimum sample size for the study was taken as 385 assuming that $50 \%$ of pregnant women were having poor knowledge on iodized salt. This was inflated by $10 \%$ to cover up possible termination of pregnancies during the period and the dropouts. Therefore, it was decided to enroll 425 pregnant women for the study.

The data collection tool used was an interviewer administered questionnaire. It was pre-tested among ten pregnant women to check the feasibility of the questions and the necessary modifications and corrections were made on the questionnaire before it was finally administered. Ethical approval for the study was obtained from the Ethical Review Committee of the Faculty of Medicine University of Ruhuna.

The questionnaire consisted of questions related to knowledge on iodized salt, sources of knowledge and questions related to practices of iodized salt usage. In the analysis, scores were given to each question related to knowledge and practices separately. The participants who scored above the mean for knowledge questions were considered as having good knowledge while others (below the mean level) were considered as having poor knowledge. Similarly, subjects who scored above the mean for questions related to practices were considered as having proper practice about the usage of iodized salt while others were considered as having improper practices. The questions related to sources of knowledge were analyzed separately. The answer sheets were checked for completeness and the data were entered to Statistical Package for the Social Sciences (SPSS version 19, SPSS Inc., Chicago, Illinois, USA) for analysis.

\section{Results}

Altogether 425 pregnant women responded to the questionnaire. The answers given by them are summarized in Table 1. Out of 425 subjects 397 (93.4\%) were aware of iodized salt and 304 (71.5\%) identified that consumption of iodized salt is essential. Majority (83.5\%) were aware of the fact that iodine deficiency had a significant influence on the body and $90.1 \%$ knew that iodine deficiency causes the goiter. However, only $50.8 \%$ had the knowledge about the connection between iodine and thyroid hormones. Nearly $52 \%$ of pregnant women knew that iodized salt is especially important during pregnancy and worthwhile to note that $48.2 \%$ were not aware of the importance of iodized salt during pregnancy.

It was observed that the subjects received information on the importance of consuming iodized salt during pregnancy, through the media (36.5\%) such as radio, television, newspapers, etc., from PHMs (35.5\%) and from both sources (14.2\%). It was interesting to note that only $2.4 \%$ of study subjects revealed that they were educated about the importance of iodized salt during pregnancy by medical personnel (i.e., medical officer of health $(\mathrm{MOH})$, family doctor, Consultant Obstetricians).

In the study sample, 259 (61\%) of pregnant women were in their second pregnancy or more. Of those only $142(55 \%)$ reported that they were educated about the importance of iodine during the previous pregnancies at the clinics while others (45\%) have not received such information. Of those who were 
educated during past pregnancies, 96.5\% received information through the public health midwives either at the clinics or while doing field visits. Table 1 illustrates their responses on the questions related to knowledge and the subjects were with a satisfactory awareness about the iodized salt and the availability.

When considering their knowledge about the correct usage of salt, $206(48.5 \%)$ mothers were of the view that adding salt after cooking is the correct way. Some $(28.7 \%)$ did not have any idea on the correct usage where as $22.8 \%$ of them felt that salt should be added before cooking.

The overall analysis revealed that $60 \%$ of pregnant women in this study sample had a knowledge score of above the mean and they were considered as having good knowledge on iodized salt, iodine and its importance while the remainder was otherwise. However, less than $50 \%$ of subjects were aware of the bad consequences of maternal iodine deficiency on their babies.
The data on the practices of iodized salt usage are given in Table 2. Even though the pregnant women had adequate knowledge on iodized salt only $6.8 \%$ of them were following the correct practice of adding salt after cooking while majority (66.8\%) used to add salt before cooking. The rest (26.4\%) were following both practices.

When buying salt from the market, majority of the subjects $(81.9 \%)$ had the practice of buying any brand of salt available at the market and only few of them $(18.1 \%)$ were used to purchase the same brand always. Majority (64.9\%) of subjects purchased both powdered and crystal salt and $19.3 \%$ and $15.8 \%$ of them consumed only powdered salt and crystal salt respectively.

In summary $50.8 \%$ of pregnant women were found to have scores given for proper practices above the mean score while $49.2 \%$ had improper practices on iodized salt usage.

Table1: Responses to the questions on knowledge

\begin{tabular}{lrr}
\hline & \multicolumn{2}{r}{ Correct answer (n=425) } \\
\cline { 2 - 3 } Knowledge regarding iodized salt & $\mathbf{n}$ & $\mathbf{\%}$ \\
\hline Awareness of iodized salt & 304 & 71.5 \\
Necessity of iodized salt intake & 389 & 91.5 \\
Availability of iodized salt in the local market & 44 & 10.3 \\
Legality of selling of uniodized salt in Sri Lanka? & & \\
\hline Knowledge on the conditions that occur due to deficiency of iodine & 70 & 16.5 \\
Significant influence on the body & 383 & 90.1 \\
Causes goiters & 216 & 50.8 \\
Impact on hormone production by the thyroid gland & & \\
\hline Effects of iodine deficiency in pregnancy & 218 & 51.8 \\
Special importance of iodized salt during pregnancy & 199 & 46.8 \\
Effect on physical development of the child & 200 & 47.1 \\
Direct effect on the brain development of the child & 204 & 48.0 \\
Effect on future education of the child & & \\
\hline Salt in food preparation & 97 & 22.8 \\
Add salt before cooking & 206 & 48.5 \\
Add salt after cooking & 122 & 28.7 \\
No idea & & \\
\hline
\end{tabular}


Table 2: Practices of using iodized salt $(n=425)$

\begin{tabular}{lrr}
\hline Household practices & n & \% \\
\hline Adding salt to food & & \\
$\quad$ Before cooking & 284 & 66.8 \\
After cooking & 29 & 6.8 \\
$\quad$ Both & 112 & 26.4 \\
\hline Purchase the same brands & & \\
$\quad$ Yes & 77 & 18.1 \\
No & 348 & 81.9 \\
\hline Type of salt consumed & & \\
Powdered & 82 & 19.3 \\
Rock salt & 67 & 15.8 \\
Both & 276 & 64.9 \\
\hline
\end{tabular}

Effect of socio-demographic characteristics of pregnant women on their level of knowledge and practices on the usage of iodized salt

The level of knowledge was compared with sociodemographic status of study subjects and is presented in Table 3. Majority of the subjects belonged to the age category of 26 - 35 years. Forty two percent of the sample had education above Advanced Level. The level of knowledge showed significant associations with age $(\mathrm{p}<0.001)$, level of education $(\mathrm{p}<0.001)$ and social class $(\mathrm{p}=0.007)$.

A similar analysis was done comparing the practices on iodized salt usage, with different sociodemographic characteristics of pregnant women (Table 4). There were no significant associations between age groups $(p=0.43)$; levels of education $(p=0.78)$ and social classes of the subject $(p=0.35)$ with the practices of salt usage among pregnant women.

Table 3: Socio-demographic characteristics on the level of knowledge

\begin{tabular}{|c|c|c|c|c|c|c|}
\hline \multirow{3}{*}{ Characteristics } & \multicolumn{4}{|c|}{ Knowledge level } & \multirow[t]{3}{*}{$\chi^{2}$} & \multirow[t]{2}{*}{ p-value } \\
\hline & \multicolumn{2}{|c|}{ Good } & \multicolumn{2}{|c|}{ Poor } & & \\
\hline & $\mathbf{n}$ & $\%$ & $\mathbf{n}$ & $\%$ & & \\
\hline
\end{tabular}

Age group in year $s$

\begin{tabular}{lrrrrrr}
$16-25$ & 52 & 12.3 & 86 & 20.3 & & \\
$26-35$ & 163 & 38.4 & 79 & 18.6 & 48.35 & $\mathrm{p}<0.001$ \\
$=36$ & 39 & 9.2 & 5 & 1.2 & & \\
\hline Total* $^{*}$ & $\mathbf{2 5 4}$ & $\mathbf{5 9 . 9}$ & $\mathbf{1 7 0}$ & $\mathbf{4 0 . 1}$ & &
\end{tabular}

\section{Level of education}

\begin{tabular}{lrrrrrr} 
Primary \& sec. & 30 & 7.1 & 70 & 16.6 & & \\
Passed O/L & 87 & 20.6 & 58 & 13.7 & 54.94 & $\mathrm{p}<0.001$ \\
Passed A/L \& above & 135 & 32.0 & 42 & 10.0 & & \\
Total* * & $\mathbf{2 5 2}$ & $\mathbf{5 9 . 7}$ & $\mathbf{1 7 0}$ & $\mathbf{4 0 . 3}$ & & \\
\hline
\end{tabular}

\begin{tabular}{lrrrrrr}
\hline Social class & & & & & & \\
Class - I \& II & 48 & 11.3 & 20 & 4.7 & & \\
Class - III \& IV & 132 & 31.1 & 81 & 19.1 & 7.25 & $\mathrm{p}=0.007$ \\
Class - V\&VI & 75 & 17.6 & 69 & 16.2 & & \\
\hline Total & $\mathbf{2 5 5}$ & $\mathbf{6 0 . 0}$ & $\mathbf{1 7 0}$ & $\mathbf{4 0 . 0}$ & & \\
\hline
\end{tabular}

*One subject $\mathrm{n}$ ot responded, ${ }^{* *}$ Three subjects not respon ded, chi-square test for trend was applied 
Table 4: Association of the practices of pregnant wo men on salt usage with their Socio-demographic characteristics

\begin{tabular}{|c|c|c|c|c|c|c|}
\hline \multirow{3}{*}{ Characteristics } & \multicolumn{4}{|c|}{ Practice of adding salt during cooking } & \multirow{3}{*}{$\chi^{2}$} & \multirow{3}{*}{ p-value } \\
\hline & \multicolumn{2}{|c|}{ Proper } & \multicolumn{2}{|c|}{ Inadequate } & & \\
\hline & $\mathbf{n}$ & $\%$ & $\mathbf{n}$ & $\%$ & & \\
\hline \multicolumn{7}{|l|}{ Age group in years } \\
\hline $16-25$ & 66 & 15.6 & 72 & 17.0 & & \\
\hline $26-35$ & 123 & 29.0 & 119 & 28.1 & 1.69 & 0.43 \\
\hline$\geq 36$ & 26 & 6.1 & 18 & 4.2 & & \\
\hline Total* & 215 & 50.7 & 209 & 49.3 & & \\
\hline \multicolumn{7}{|l|}{ Level of education } \\
\hline Primary \& sec. & 54 & 12.8 & 46 & 10.9 & & \\
\hline Passed $\mathrm{O} / \mathrm{L}$ & 72 & 17.1 & 73 & 17.3 & 0.50 & 0.78 \\
\hline Passed A/L \& above & 89 & 21.0 & 88 & 29.9 & & \\
\hline Total** & 215 & 50.9 & 207 & 49.1 & & \\
\hline \multicolumn{7}{|l|}{ Social class } \\
\hline Class - I \& $\mathrm{II}^{1}$ & 38 & 8.9 & 30 & 7.1 & & \\
\hline Class - III \& IV ${ }^{2}$ & 101 & 23.8 & 112 & 26.3 & 2.08 & 0.35 \\
\hline Class $-\mathrm{V}^{3}$ & 75 & 17.6 & 65 & 15.3 & & \\
\hline Class $-\mathrm{VI} * *^{3}$ & 2 & 0.5 & 2 & 0.5 & & \\
\hline Total & 216 & 50.8 & 209 & 49.2 & & \\
\hline
\end{tabular}

*One subject not responded, ${ }^{* *}$ Three subjects not responded, chi-square test for trend was applied

\section{Discussion}

Two decades have passed since the implementation of the national salt iodization programme in Sri Lanka but there have not been any studies done among pregnant women to assess the knowledge and practices related to iodized salt and its usage. Even in countries with very good iodine nutrition, there is evidence that pregnant women are susceptible to iodine deficiency $(8,9)$.

Iodized salt is the main source of dietary iodine in Sri Lankan population and it has been the main strategy to control the iodine deficiency disorders. In this study sample most of the pregnant women $(>90 \%)$ were aware of iodized salt and about $90 \%$ knew the connection between iodine deficiency and goiter.
Yet, only about half of the subjects $(51.8 \%)$ were aware of the importance of consumption of iodized salt especially during pregnancy. This shows that the public awareness about iodized salt is not satisfactory. Similar results have been reported in studies done in Ghana a developing country in subSaharan Africa, where $>90 \%$ of subjects heard about iodized salt and about 33\% knew iodine deficiency causes goiter (10) and in Iraq, Ebrahim and Muhammed (11) reported that $>92 \%$ of subjects heard about iodized salt and only $27.1 \%$ knew about the health benefits.

Of the pregnant women who were in their second pregnancy or more $(n=259), 45 \%$ have not received information on the importance of iodine during 
previous pregnancies from health workers at antenatal clinics. Further, more than half the numbers of pregnant women were not aware of possible harmful effects of iodine deficiency on the foetus during pregnancy and later, on the newborn. Jooste $e t$ al., (12) in 2004 reported a very low level of knowledge in their study (only $3.9 \%$ had considered brain damage, as the most important health consequence of iodine deficiency) on iodine nutrition among the mothers in African region. However, in the present study $60 \%$ of subjects had a good knowledge about iodized salt and iodine. When considering the good literacy rate in Sri Lanka (13), the level of knowledge in our population can expected to be better. These results showed that the overall knowledge about importance of iodine, especially during pregnancy is not satisfactory in this study sample.

The area selected for the study is close to the main city of the Southern province and almost all pregnant women attended the antenatal clinics at main tertiary care unit in the province where good antenatal care facilities are available. Although 3/4 of the study subjects, generally had educational qualifications above the basic (passed O/L or above) in this setting, the knowledge on iodine was not satisfactory. Therefore situation may even be worse in other under developed areas of the country.

It is important to know, how the pregnant women receive knowledge about the importance of iodine during pregnancy. Majority of study subjects $(86.2 \%)$ received the knowledge through public media and PHM's. This is probably due to the health education programmes frequently conducted through television and radios and the health talks given by PHM at the antenatal field clinics. The lack of involvement of medical personnel in health education at the clinics may be due to their busy schedules and heavy work load and it's a drawback in the present health care delivery system.

It has also been observed in the present study that the association of the age of mothers, their level of education and social class are associated with the level of knowledge in them on iodized salt and iodine. With advancing age their level of knowledge has increased and this may probably be due to the fact that they acquire more knowledge and experiences with the maturity. The results showed that higher the educational level, their level of knowledge regarding iodine nutrition is also higher. Apart from that the study subjects who belonged to higher social class had a better knowledge on iodine

There were many brands of iodized salt available in the market. A previous study revealed that forty two brands of salt with varying degrees of iodine levels were available in the study area (6). Majority $(81.9 \%)$ of pregnant women have indicated that they used to buy any brand of salt available in the market. This can be considered as a good practice in one hand because they might be getting the salt products with high, low and average iodine contents and ultimately they might be getting the average amount of iodine which is required. On the other hand if they used to buy the same brand of salt probably with low iodine content for a longer period, they might have iodine deficiency.

Even though some of the selected factors such as age, level of education and social class showed a highly significant association with the level of knowledge, when it came to practice of the study subjects, regarding the usage of iodized salt, it did not show any significant associations with above factors. This shows that, though they have a good knowledge on iodine and iodized salt they did not put it in to practice. The reason for that may be their lack of understanding of the gravity of IDD as a significant health problem.

In conclusion, overall knowledge about iodine and iodized salt in this study population is not satisfactory and about half of the subjects had improper practices related to the iodized salt usage, even after two decades of the implementation of national salt iodization programme. Public media and PHM's appear to play a major role in health education but the lack of involvement of medical personnel in imparting the necessary information seems to be a critical issue. The unsatisfactory level of knowledge on iodine and iodized salt may result in iodine deficiency during pregnancy and more over poor correlation between the good knowledge and proper practices is an issue to be addressed. To resolve this public health issue it is important to intensify health educational programmes at various levels including schools etc. expressing the importance of eliminating IDD. Health teams who are responsible for the antenatal care must be educated about conveying the message regarding the importance of iodine nutrition during pregnancy 
in a more meaningful way to the public. It may also be helpful if educational leaflets that carry precise information regarding importance of iodine in pregnancy are made available though antenatal clinics at booking visit.

\section{Acknowledgements}

We wish to acknowledge the University Grants Commission, Sri Lanka and the project of Transforming University of Ruhuna in to International Level (TURIS project) for the financial assistance provided for the project.

\section{References}

1. Jayatissa R, Gunathilake MM, Fernando DN. Iodine nutrition status among schoolchildren after salt iodization. The Ceylon Medical Journal 2005; 4(50): 144-148.

2. Shekar M, Somanathan A, Lidan Du. Malnutrition in Sri Lanka: Scale, Scope, Causes, and Potential Response. Health, Nutrition and Population Human Development Network Human Development Unit South Asia Region; Report No. 40906-LK 2007.

3. Jayatissa R, Gunathilaka MM. Third National Survey on Iodine Deficiency Status in Sri Lanka UNICEF and Ministry of Health 2012.

4. World Health Organization. Iodine status worldwide: WHO Global Database on Iodine Deficiency 2004.

5. Jayatisa R, Gunathilaka MM, Ranbanda JM, et al. Iodine status of pregnant women in Sri Lanka. Sri Lanka Journal of Diabetes, Endocrinology and Metabolism 2013;3:4-7.
6. De Zoysa GED, Hettiarachchi M, Jayathilaka KAPW, Liyanage C. Elimination of iodine deficiency disorders (IDD) in Sri Lanka: does our salt industry comply with SLS guidelines for salt industry? The Ceylon Medical Journal 2012; 57(Supp.1): 119.

7. Lowanga SK, Lameshow S, Sample size determination in health studies: a practical manual. WHO, Geneva 1991.

8. Bath SC, Walter A, Taylor A, Wright J, Rayman MP, Iodine deficiency in pregnant women living in the South East of the UK: the influence of diet and nutritional supplements on iodine status. British Journal of Nutrition 2014; 111(9): 1622-31.

9. Caldwell KL, Pan Y, Mortensen ME, et al. Iodine status in pregnant women in the National Children's Study and in U.S. women (15-44 years), National Health and Nutrition Examination Survey 2005-2010. Thyroid 2013; 23(8): 92737.

10. Buxton C, Baguune B. Knowledge and practices of people in Bia District, Ghana, with regard to iodine deficiency disorders and intake of iodized salt. Archives of Public Health 2012; 70: 5. http://www.archpublichealth.com/ content/70/1/5.

11. Ebrahim SM, Muhammed NK. Consumption of iodized salt among households of Basra city, south Iraq. Eastern Mediterranean Health Journal 2012; 18(9): 980-4.

12. Jooste PL, Upson N, Charlton KE. Knowledge of iodine nutrition in the South African adult population. Public Health Nutrition 2004; 8(4): 382-386.

13. Sri Lanka Labour Force Survey Annual Report. Department of Census and Statistics Ministry of Finance and Planning $2012 ; 32$. 